\title{
DETERMINANTS OF PATIENT SATISFACTION ON INTERIOR DESIGN QUALITY OF PUBLIC HOSPITALS IN MALAYSIA
}

\author{
Shariffah Syafiqah Aljunid ${ }^{1}$, Nurul Nabilah Huda Mohamad Shukri² ${ }^{2}$, Mohd Zafrullah Mohd Taib ${ }^{3}$ and \\ Zanariah Abu Samah ${ }^{4}$ \\ 1, 3, ${ }^{4}$ Faculty of Architecture, Planning \& Surveying, Universiti Teknologi MARA, Malaysia \\ ${ }^{2}$ Faculty of Agriculture, Universiti Putra Malaysia
}

\begin{abstract}
Being in a hospital can be a stressful experience especially to the patients. The importance of design quality as a trigger to patients' satisfaction is becoming a topic of significant relevance as it also impacts the building operation. This study aims to determine the factors influencing the patients' satisfaction toward the interior design quality of inpatient units at public hospitals in Malaysia. Self-administered questionnaires were distributed among 483 inpatients from 5 Obstetrics and Gynaecology wards at public hospitals in the Klang Valley region. The Structural Equation Model (SEM) technique was applied to examine the causal relationship and to test the hypothesis of the patients' satisfaction toward the interior design quality. The results revealed that space planning $(B=0.265)$, lighting $(B=0.263)$, furniture $(B=0.243)$, and color $(B=0.138)$ have a significantly positive effect on patients' satisfaction toward the interior design quality. Whereas way-finding, safety, air quality and accessibility have no significant effect on the patients' satisfaction. This study concludes that certain qualities of interior design have great impact on patients' satisfaction. The findings proved that revamping the inpatient units' space planning can lead to significant patient experience improvements, while the aspect of accessibility is the least concern to the patients when they stay in the hospital. This study provides input to help designers, architects and hospital planners to evaluate their priorities in planning and designing better hospitals in the future.
\end{abstract}

Keywords: Design quality, Interior design, Patient satisfaction, Inpatient, Public hospital, Structural equation model

\section{INTRODUCTION}

The most important measure in any evaluation of a building's design is whether it satisfies user requirements and what users think and feel about it ${ }^{1}$. In healthcare facilities, patient satisfaction is commonly used as a principal measure of quality that covers both clinical and physical aspects ${ }^{2}$. Patient satisfaction is a very effective quality indicator as it represents the performance of the hospital. Understanding the patient experience is crucial as it provides the opportunity for improvement $^{3}$. In fact a Patient's Satisfaction Unit that had been set up at Penang Hospital in Malaysia recently proved that this technique is known to solve issues in public hospital settings in Malaysia ${ }^{4}$. Many reviews have been done on the effects of physical environment on their health outcomes ${ }^{5,6,7}$. The design of a healthcare facility can have both positive and negative effects on the users ${ }^{8}$. However, according to a previous study ${ }^{9}$, being in a hospital is especially stressful to the patients. Considering the growing need for a supportive and quality environment in healthcare facilities to encourage healing among patients, healthcare interior design field has gained great attention and became increasingly important over the past few years.

Hospital building is one of the most complex types to design due to being commanded by many regulations and technicalities. Hospital buildings are often under great pressure to cater for intense situations. For this reason, this facility should be designed and built responsibly to ensure that the spaces are comfortable to the users especially patients. There are several important keys in designing good hospitals. Fundamentally, a good hospital design should be able to improve the organisation's clinical, economic, productivity, satisfaction, and cultural measures ${ }^{10}$. Given the fact that the quality of patients' experience is being directly influenced by the quality of the interior environment, aspects that could contribute to achieving good quality design should not be disregarded by any means. Additionally, in healthcare sectors, the physical environment quality is also considered as one of the dimensions to define its service quality ${ }^{11}$.

Indicators of quality design can be measured objectively, depending on the subjective views, experiences and preferences ${ }^{12}$. In interior design, the aspects of quality are described to fit both visual and functional purposes. The interior spaces within a building are defined by the architectural elements of structure and enclosures including floors, ceilings, walls, windows, doorways and stairways ${ }^{13}$. Besides that, elements that describe a good quality design should make interior spaces habitable-functional fit, aesthetically pleasing and psychologically satisfying for activities ${ }^{14}$. It is further elaborated that the quality dimensions of interior design should include the productivity, health protection, safety and welfare of the occupants. Furthermore, the outcome of a past study ${ }^{15}$ suggested that an interior environment contributes to healing should include safety, ergonomics, artwork, outdoor view, furniture and 
furnishings, ambience and therapies. Factors such as color, shape, lighting, smell, sound and feel should also be part of the requirement ${ }^{16}$. Similarly, the use of color, furniture, art and lighting are recommended to be among the design considerations to promote wellness to the patients ${ }^{17}$. The importance of a successful wayfinding system, accessibility and material selections in healthcare facilities have also been emphasised $^{18}$.

Despite the continuous efforts to upgrade existing healthcare facilities, hospital design in Malaysia is still in need of improvement ${ }^{19}$. Concerns about the flaws in current hospital design trend have been conveyed in an article $e^{20}$, claiming that the latest hospital design is unaesthetic, inconvenient and dangerous to the users. There are also numerous studies related to healthcare facilities design reported by local researchers contributing to various issues in hospital buildings in Malaysia ${ }^{21}$, 22. This paper is aimed at filling the gap that exists in the literature by conducting a study on five inpatient units within the Klang Valley region, focusing particularly on the interior design aspects since this approach was not given much attention before. The main objective of this study is to explore the possible factors influencing the patients' satisfaction towards the interior design quality of inpatient units at public hospitals in Malaysia. This paper is as an attempt to gather information for the purpose of attaining an evident-based interior design framework for inpatient units of public hospitals in this country.

\section{METHODOLOGY}

A self-administered questionnaire was formulated and developed based on the body of literature review and previous studies that are relevant to the topic. The questionnaire was developed through modification and review process of past post-occupancy and user satisfaction forms. In a hospital setting, inpatients might be more vulnerable to stress than outpatients. Inpatients are expected to be in poor health, more physically and psychologically impaired. They may also be emotionally vulnerable to be participating in any forms of survey. Since the respondents were inpatients, their clinical conditions were therefore taken into consideration by customising the sets of questions to make them simpler and straightforward to be answered. Respondents were asked to rate their level of satisfaction of items on Likert type scale, ranging from 1 to 5 (1 = Completely Dissatisfied, 2 = Dissatisfied, 3 = Neutral, 4 = Satisfied, and $5=$ Completely Satisfied), a higher score indicating a higher level of satisfaction of the item. The questions were narrowed down focusing particularly on the aspects of interior design such as space planning, accessibility, wayfinding, air quality, colour, lighting, furniture and safety. The proposed research model is presented in Figure 1.

The responses from patients were gathered through the distribution of questionnaires in five public hospitals that were selected using purposive sampling method. Four general hospitals labelled Hospital A, Hospital B, Hospital C, Hospital D and a teaching hospital, labelled as Hospital E were chosen. These hospitals act as a subset representing all public hospitals in Malaysia. All of them were selected based on having the same criteria such as their type, location, facilities and services that they offer within the communities. They are comparable in general and among the common types of hospitals that are available in the country. The same sampling technique was applied to choose a department for the purpose of this study since these hospitals provide a wide range of services from a vast number of special departments. Obstetrics and Gynecology departments were selected grounded on the fact that these departments have the highest number of patients turn over and the busiest departments in the hospitals. A total of 500 questionnaires were distributed to the respondents from all five hospitals. However, 483 usable questionnaires were analysed, which gave a valid response rate of $97 \%$. The distribution of questionnaires was completed in 60 days.

\section{DATA ANALYSIS}

This study employed two types of analysis, which are descriptive and infrential analysis. Descriptive analysis describes the characteristics of respondents in this study by percentage and frequency. While, inferential analysis is to describe and to make inferences about the population from which the samples were taken. IBM SPSS AMOS 23 was used to analyze and construct the Structural Equation Model (SEM) method. Eight hypothesis were formulated from the literature, in which space planning, accessibility, furniture, wayfinding, lighting, air quality, safety, and color will induce a positive effect on the quality design. The direct effect on SEM is a multivariate analysis that requires all variables to satisfy the assumption of normality, homogeneity and outlier to proceed with the SEM. In SEM, a Confirmatory Factor Analysis (CFA) was carried out to asses the validity and reliability of a latent construct. Also, this is to determine how well the model would fit the data. CFA was conducted, prior to modeling the causal effects for the multiple latent constructs in SEM. The following table presents the cutting point for the model fitness index. 


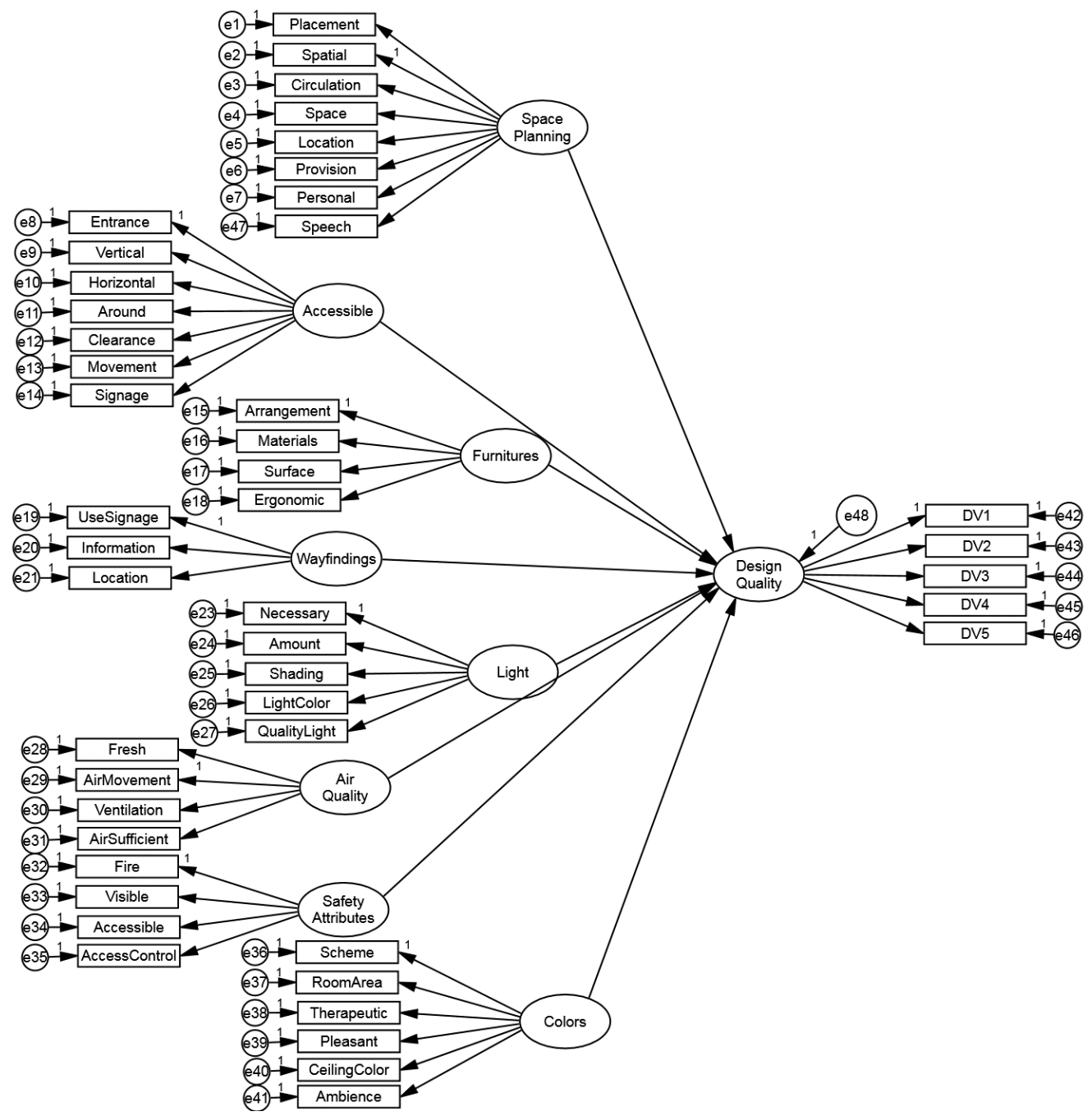

Figure 1: Research Model

Table 1: Model Fit and Acceptance Level ${ }^{23}$

\begin{tabular}{|c|c|c|c|}
\hline $\begin{array}{l}\text { Name of } \\
\text { Category }\end{array}$ & Name of Index & $\begin{array}{c}\text { Level of } \\
\text { Acceptance }\end{array}$ & Literature \\
\hline \multirow[t]{3}{*}{ Absolute Fit } & Discrepancy Chi-Square & P- value $<0.05$ & \\
\hline & $\begin{array}{l}\text { Root Mean Square of Error } \\
\text { Approximation }\end{array}$ & RMSEA $<0.08$ & Browne \& Cudeck (1993) \\
\hline & Goodness of Fit Index & $\mathrm{GFI}>0.90$ & Joreskog \& Sorbom (1984) \\
\hline \multirow[t]{4}{*}{ Incremental Fit } & Adjusted Goodness of Fit & AGFI $>0.90$ & Tanaka \& Huba (1985) \\
\hline & Comparative Fit Index & $\mathrm{CFI}>0.90$ & Bentler (1990) \\
\hline & Tucker - Lewis Index & $\mathrm{TLI}>0.90$ & Bentler \& Bonett (1980) \\
\hline & Normed Fit Index & $\mathrm{NFI}>0.90$ & Bollen (1989) \\
\hline $\begin{array}{l}\text { Parsimonious } \\
\text { Fit }\end{array}$ & $\begin{array}{l}\text { Chi- Square / Degrees of } \\
\text { Freedom }\end{array}$ & Chisq $/ \mathrm{df}<5$ & Marsh \& Hocevar (1985) \\
\hline
\end{tabular}

If the indices do not achieve the required level as shown in Table 1 , any items with factor loading less than $0.5, \mathrm{R}^{2}$ less 0.4 , and a negative sign will be deleted from the model to avoid the model fitness index from being affected. Once the CFA procedure is completed for all latent factors, the next step is to identify the validity and reliability of the constructs in the measurement model. The requirement for validity is when the Average Variance Extracted (AVE) exceeds 0.50 and the Composite Reliability (CR) are greater than $0.70^{31}$. Then, the normality distribution of the data was assessed before proceeding to modeling the structural model. The value of skewness should be between -1.0 to 1.0 which will indicate the data as being normally distributed. Meanwhile, the value of Kurtosis should not exceed 7.0. Outliers in the dataset was determined by the Mahalanobis distance. The presence of outliers defined as the distance of certain observation is too far from the others, were deleted in order to improve the normality. The significance of the coefficient will be then identified. 


\section{RESULTS}

Table 2 reports the demographic profile of the respondents such as gender, age, race, religion, marital status, residential area, educational level and employment. The demography of the respondents is represented solely by female since the study was conducted in Obstetrics and Gynaecology departments. Distribution by ethnicity shows that the majority of the respondents were Malays (87.16\%). Patients were represented mostly by Muslims $(89.86 \%)$ and aged between 25-35 (64.39\%). Findings also showed most respondents live in the urban areas (93.00\%).

Table 2: Demographics of Respondents

\begin{tabular}{|c|c|c|}
\hline Characteristics & Frequency & Percentage \\
\hline \multicolumn{3}{|l|}{ Race } \\
\hline Malay & 421 & 87.16 \\
\hline Chinese & 32 & 6.63 \\
\hline Indian & 14 & 2.90 \\
\hline Others & 16 & 3.310 \\
\hline \multicolumn{3}{|l|}{ Religion } \\
\hline Islam & 434 & 89.86 \\
\hline Christian & 14 & 2.90 \\
\hline Buddha & 23 & 4.76 \\
\hline Hindu & 12 & 2.48 \\
\hline \multicolumn{3}{|l|}{ Age (years) } \\
\hline $15-25$ & 62 & 12.84 \\
\hline $25-35$ & 311 & 64.39 \\
\hline $35-45$ & 92 & 19.05 \\
\hline $45-55$ & 11 & 2.28 \\
\hline Above 58 & 2 & 0.41 \\
\hline \multicolumn{3}{|l|}{ Area } \\
\hline Urban & 449 & 93.00 \\
\hline Rural & 34 & 7.00 \\
\hline \multicolumn{3}{|l|}{ Education Level } \\
\hline Non-Formal & 4 & 0.83 \\
\hline Primary & 4 & 0.83 \\
\hline Secondary & 161 & 33.33 \\
\hline Diploma & 130 & 26.92 \\
\hline Degree & 158 & 32.71 \\
\hline Masters & 22 & 4.55 \\
\hline Doctorate & 4 & 0.83 \\
\hline \multicolumn{3}{|l|}{ Marital Status } \\
\hline Single & 25 & 5.18 \\
\hline Married & 455 & 94.2 \\
\hline Divorced & 2 & 0.41 \\
\hline Widowed & 1 & 0.21 \\
\hline \multicolumn{3}{|l|}{ Employment } \\
\hline Government & 145 & 30.02 \\
\hline Retired & 5 & 1.04 \\
\hline Unemployed & 70 & 14.49 \\
\hline Private & 256 & 53.00 \\
\hline Student & 7 & 1.45 \\
\hline
\end{tabular}

The educational level of the respondents is one of the major characteristics that could influence their responses because respondents with different educational status may have different expectations toward the hospital's environment.
The majority (33.33\%) of the respondents were high school graduates, whereas $32.71 \%$ of the respondents have bachelor degrees, $26.92 \%$ of the respondents have diplomas, while, $5.38 \%$ of them have a higher degree. The remaining respondents 
(1.66\%) have a qualification of primary school level and below. Table 2 also shows, most of the respondents were married $(94.20 \%)$, while, (5.18\%) were single and the remaining $(0.62 \%)$ were divorcees and widowers. The employment of the respondents was categorized into six groups. The highest numbers of respondents were working-class people in private sectors (53.00\%) and working-class people in various positions in the government sectors $(30.02 \%)$, whereas, the rest were unemployed $(14.49 \%)$, students $(1.45 \%)$ and retired $(1.04 \%)$.

The following table shows the assessment of the validity and reliability for latent constructs. The results of Average Variance Extracted (AVE) for the seven factors were greater than 0.50 which exceeded the recommended validity ${ }^{31}$, except for the wayfinding. The AVE value for wayfinding was closer to 0.5 and considered adequate. The composite reliability of 0.7 or above was deemed acceptable 32,33 . Therefore, it can be concluded that convergent validity has been established. Also, the loadings for each item were the highest for their designated constructs. Thus, discriminant validity is achieved. Further, normality issues were not present in the dataset as the value of skewness were between -1.0 to 1.0 and the values of Kurtosis did not exceed 7.0. Additionally, the Mahalanobis $\mathrm{d}^{2}$ shown to be less than $\mathrm{X}^{2}$ indicating no potential outliers.

Table 3: Result of CFA for measurement model

\begin{tabular}{|c|c|c|c|c|}
\hline \multirow[b]{2}{*}{ Construct } & \multirow[b]{2}{*}{ Item } & \multicolumn{3}{|c|}{ Convergent Validity } \\
\hline & & $\begin{array}{l}\text { Factor } \\
\text { Loading }\end{array}$ & $\begin{array}{l}\text { Average Variance } \\
\text { Extracted (AVE) }\end{array}$ & $\begin{array}{c}\text { Composite } \\
\text { Reliability (CR) }\end{array}$ \\
\hline \multicolumn{5}{|c|}{ Space Planning $\left(X^{2}=4.333, C F I=0.978, R M S E A=0.08\right)$} \\
\hline & Placement & 0.808 & 0.662 & 0.94 \\
\hline & Spatial & 0.84 & & \\
\hline & Circulation & 0.85 & & \\
\hline & Space & 0.867 & & \\
\hline & Location & 0.752 & & \\
\hline & Provision & 0.883 & & \\
\hline & Personal & 0.748 & & \\
\hline & Speech & 0.755 & & \\
\hline \multicolumn{5}{|c|}{ Accessibility $\left(X^{2}=4.518, C F I=0.980, R M S E A=0.08\right)$} \\
\hline & Entrance & 0.768 & 0.691 & 0.929 \\
\hline & Vertical & 0.84 & & \\
\hline & Horizontal & 0.835 & & \\
\hline & Around & 0.861 & & \\
\hline & Clearance & 0.809 & & \\
\hline & Movement & 0.851 & & \\
\hline & Signage Quantity & 0.688 & & \\
\hline \multicolumn{5}{|c|}{ Furniture $\left(X^{2}=3.491, C F I=0.997, R M S E A=0.07\right)$} \\
\hline & Arrangement & 0.89 & 0.799 & 0.942 \\
\hline & Materials & 0.925 & & \\
\hline & Surface & 0.931 & & \\
\hline & Ergonomic & 0.835 & & \\
\hline \multicolumn{5}{|c|}{ Wayfinding $\left(X^{2}=3.282, C F I=0.988, R M S E A=0.06\right)$} \\
\hline & Use Signage & 0.643 & 0.466 & 0.715 \\
\hline & Information & 0.512 & & \\
\hline & Location & 0.85 & & \\
\hline \multicolumn{5}{|c|}{ Lighting $\left(X^{2}=2.072, C F I=0.996, R M S E A=0.04\right)$} \\
\hline & Necessary & 0.718 & 0.628 & 0.893 \\
\hline & Amount & 0.806 & & \\
\hline & Shading & 0.788 & & \\
\hline & Light Color & 0.81 & & \\
\hline & Quality Light & 0.827 & & \\
\hline
\end{tabular}


Table 4: Result of CFA for measurement model (continued)

\begin{tabular}{|c|c|c|c|c|}
\hline \multirow[b]{2}{*}{ Construct } & \multirow[b]{2}{*}{ Item } & \multicolumn{3}{|c|}{ Convergent Validity } \\
\hline & & $\begin{array}{c}\text { Factor } \\
\text { Loading }\end{array}$ & $\begin{array}{l}\text { Average Variance } \\
\text { Extracted (AVE) }\end{array}$ & $\begin{array}{c}\text { Composite } \\
\text { Reliability (CR) } \\
\end{array}$ \\
\hline \multicolumn{5}{|c|}{ Air Quality $\left(X^{2}=1.466, C F I=0.999, R M S E A=0.031\right)$} \\
\hline & Fresh & 0.85 & 0.77 & 0.933 \\
\hline & Air Movement & 0.868 & & \\
\hline & Ventilation & 0.9 & & \\
\hline & Air Sufficient & 0.904 & & \\
\hline \multicolumn{5}{|c|}{ Safety Attributes $\left(X^{2}=4.510, C F I=0.995, R M S E A=0.08\right)$} \\
\hline & Fire & 0.883 & 0.712 & 0.911 \\
\hline & Visible & 0.918 & & \\
\hline & Accessible & 0.907 & & \\
\hline & Access Control & 0.662 & & \\
\hline \multicolumn{5}{|c|}{ Colors $\left(X^{2}=4.629, C F I=0.985, R M S E A=0.08\right)$} \\
\hline & Scheme & 0.832 & 0.649 & 0.915 \\
\hline & Room Area & 0.899 & & \\
\hline & Therapeutic & 0.917 & & \\
\hline & Pleasant & 0.917 & & \\
\hline & Ceiling Color & 0.713 & & \\
\hline & Ambience & 0.47 & & \\
\hline Overall mode & $=2.847, C F I=0.909$ & & & \\
\hline
\end{tabular}

The structural model fit is acceptable with $X^{2}=$ 2.847, $\mathrm{df}=998, \mathrm{p}$-value $=0.000, \mathrm{CFI}=0.909$, RMSEA $=0.062^{31}$. Table 2 shows the results of structural model on the effect of predictors on the design quality. Furniture, space planning, lighting and color significantly contribute to determining the design quality. The highest contribution is attributed by space planning $(B=0.265)$ followed by lighting $(B=0.263)$, furniture $(B=0.243)$, and color $(B=0.138)$. In contrast, wayfinding, accessibility, safety and air quality have no significant effect on the interior design quality. Besides that, this set of factors contributed a total of 67.9 percent of the variance in patients' satisfaction level on the design quality $\left(R^{2}=.679\right)$.

Table 5: Results of SEM on effects of predictors on design quality

\begin{tabular}{cccccc}
\hline Constructs & B & S.E. & CR & P & Decision \\
\hline Wayfinding & 0.133 & 0.114 & 1.167 & 0.243 & Not Significant \\
Furniture & 0.243 & 0.06 & 4.034 & 0.000 & Significant \\
Accessible & -0.038 & 0.11 & -0.341 & 0.733 & Not Significant \\
Space Planning & 0.265 & 0.087 & 3.044 & 0.002 & Significant \\
Lighting & 0.263 & 0.099 & 2.662 & 0.008 & Significant \\
Safety & 0.029 & 0.061 & 0.476 & 0.634 & Not Significant \\
Color & 0.138 & 0.062 & 2.232 & 0.026 & Significant \\
Air Quality & 0.023 & 0.062 & 0.364 & 0.715 & Not Significant \\
\hline
\end{tabular}

\section{DISCUSSION}

The main goal of this post-occupancy study is to explore the possible predictors that would statistically influence the patients' satisfaction in terms of the interior design quality at the inpatient units. Based on the results, among the eight factors, space planning $(B=0.265)$ proved to be the most influential factor on determining the patients' satisfaction. This indicates that the patients are most likely to be affected by the provided space and its functionality. In a healthcare interior, the basic functionality of an area is when there is an efficient space that is not only aesthetically pleasing but also comfortable to the patients. This involves the understanding of the medical requirements and the users' needs. Since patient satisfaction and their quality of life are being increasingly considered in the competitive world of healthcare, the interior 
spatial area, circulation pattern and furniture layout should be a priority especially in the pursuit of creating a quality environment to the patients. The finding also shows that accessibility $(B=-0.038)$ is not an important aspect, which means that it has no effect on how the patients feel toward the interior environment. This is most probably because patients have already assumed that hospital buildings were designed and built to cater sick people. While it is important to get every detail right in a hospital design, the patients may feel that it is especially crucial to have no room for design errors in an inpatient unit particularly in regards to being accessible to people with disabilities.

Patient satisfaction has received great attention today and has become one of the main concerns of any healthcare facilities. Any organizations and building operations need the users opinion to improve its efficiency. Given the fact that patients are the main priority of the hospital, they are considered as a reliable resource in providing valuable information to interpret quality. Efforts should be made to make the patients' stay as comfortable as possible in order to improve their satisfaction. The literature has pointed to many factors that could contribute to patients' wellbeing during their stay. However, in accordance with the results of this study, it is necessary to revise the interior qualities particularly the space planning, lighting, furniture and color as they directly influence the patients' level of satisfaction.

\section{CONCLUSION}

This study is explored to provide an opportunity to use the current and emerging evidence to upgrade the interior design quality of the inpatient units in effort to improve patients' satisfaction. This study concludes that design factors such as space planning, lighting, furniture and color have a significant influence on the patients' satisfaction. On the contrary, the aspects of wayfinding, safety, air quality and accessibility do not affect their level of satisfaction. Given the expanding healthcare industry in Malaysia, a growing need for a supportive environment has gained healthcare interior design industry a great significance. Interior designers are becoming diligently committed to finding solutions to balance aesthetics and functionality in hospital building design. Since patients are already emotionally vulnerable to stress to begin with, being in a poorly thought out environment could further impede their recovery. This study fills the current gap in the literature by determining the possible design factors that are directly influencing the patient satisfaction in terms of the interior quality.

As Malaysia evolves towards becoming a more developed country, the quality of its healthcare facilities demands a more attentive investigation. With this standard, hospital buildings should be designed by considering the physical and psychological effects of the design elements on the users. Thus, specific qualities of improvement that are identified through the findings of this study should serve as a wake-up call to interior designers, architects, policy-makers, hospital managers and planners to carefully evaluate their priorities in designing better hospitals in the future. Although this study is not without limitations, it is beneficial for them to observe the qualities and aspects that are influencing patients' satisfaction in order to come up with better design corresponding strategies. Designers and architects will need to regularly adjust hospital design projects according to the varied demands of the inpatients. This study took an indicative approach to explore only one department. More specialist departments need to be covered in order to achieve more comprehensive results and better outcomes. Besides, additional studies on design quality are also required to provide further input on how to achieve a high quality indoor environment in healthcare settings especially in Malaysia.

\section{ACKNOWLEDGEMENTS}

The researchers would like to express gratitude to Universiti Teknologi MARA (UiTM) and Universiti Putra Malaysia for providing a platform to conduct this research. We also would like to acknowledge the UKM Research and Ethics committee (FF-2018002) and National Medical Research Register (NMRR-17-2426-38320) for their approvals to conduct this research.

\section{COMPETING INTEREST}

All the authors that they have no competing interest.

\section{FUNDING}

This research project did not receive any funding from any organization.

\section{REFERENCES}

1. Gann DM, Salter AJ, Whyte JK. Design Quality Indicator as a tool for thinking. Building Research \& Information. 2003; 31(5): 318 - 333.

2. Stern LA, Mac-Rae S, Gertis M, et al. Understanding The Consumer Perspective To Improve Design

Quality. Journal of Architectural and Planning Research 2003; 16-28.

3. Ibrahim YS, Mohtar S, Hassan A, et al. Patient Perception on Service Quality Improvement among Public and Private Healthcare Providers in Nigeria and Malaysia. World J Prev Med. 2015; 3(4): 84-93. 
4. Hospital sets up satisfaction unit to resolve customers' issues. The Star. https: / /www.thestar.com.my/news/co mmunity/2012/09/14/hospital-sets-upsatisfaction-unit-to-resolve-customersissues/(Assessed 13 December 2017)

5. Ulrich RS, Zimring C, Zhu $X$, et al. A review of the research literature on evidence-based healthcare design. HERD: Health Environments Research \& Design Journal 2008; 1(3): 61-125.

6. Huisman ERCM, Morales E, Hoof JV, et al. Healing environment: A review of the impact of physical environmental factors on users. Building and Environment 2012; 58: 70-80.

7. Van Den Berg AE. Health Impacts of Healing Environments. A review of evidence for benefits of nature, daylight, fresh air and quiet in healthcare settings. Groningen. The Architecture of Hospitals 2005. https: / / library.wur.nl/WebQuery/wurp ubs/338544 (Assessed 11 July 2017)

8. Akpan-idiok P, Ackley A. Sustainable Therapeutic Environment: Impacts of the Indoor Environment on Users' Perception of Wellbeing in Public Healthcare Facilities in Calabar Municipality, Nigeria. World Journal of Pharmaceutical and Medical Research. 2017; 3(6): 27-37.

9. Haltman $T$, Coakley $A B$, Annese $C D$, et al. Exploring the sleep experiences of adult patients. Creative Nursing 2012; 18: $135-139$.

10. Becker F, Parsons KS. Hospital facilities and the role of evidence-based design, Journal of Facilities Management. 2007; 5(4): 263-274.

11. Brady MK, Cronin JJ. Customer Orientation: Effects on Customer Service Perceptions and Outcome Behaviors. Journal of Service Research 2001b; 3(3): 241-251.

12. Farooqui RU, Ahmed SM. Designing for Quality: An Empirical Study of Design Quality Indicator (DQI) Tool. 7th Latin American and Caribbean Conference for Engineering and Technology 2009; 1-7.

13. Ching DK. Interior Design Ilustrated. New Jersey, US: John Wiley \& Sons 2005.
14. Samah ZA, Ibrahim N, OthmanS, Abd Wahab MH. Assessing quality design of interiors: a case study of a hospital outpatient unit in Malaysia. ProcediaSocial and Behavioral Sciences 2012; 35: 245-252.

15. Abbas MY, \& Ghazali R. Healing Environment: Paediatric Wards - Status and Design Trend. Procedia - Social and Behavioral Sciences 2012; 49 : 28-38.

16. Oberlin J. Evidence that pediatric settings can heal. Health Care Design. 2008.

http:/ / www.healthcaredesignmagazine .com $/ M E 2 /$ dirmod.asp?sid=\&nm=\&type= Publishing\&mod=Publications\%3A\%3AArt icle\&mid $=8 F 3 A 7027421841978 F 18 B E 895$ F87F791\&tier=4\&id=92860F707A534EE6 A9266DC828E2FBCA. (Assessed 17 October 2018)

17. Dijkstra K, Pieterse M, Pruyn A. Physical environmental stimuli that turn healthcare facilities into

healing environments through psychologically mediated effects: Systematic review. Journal of Advanced Nursing 2006; 56(2): 166-181.

18. Salonen $\mathrm{H}$, Lahtinen $\mathrm{M}$, Lappalainen $\mathrm{S}$, et al. Positive impacts of environmental characteristics on health and wellbeing in health-care facilities: A review. Paper presented at the Healthy Buildings 2012, 10th International Conference, Official Conference of the International Society of Indoor Air Quality and Climate conference, Brisbane, QLD, Australia, 8$12 \quad$ July 2012. https: / /eprints.qut.edu.au/54368/16/5 4368.pdf (Assessed 22 January 2017)

19. Goh NA, Tahir MM, Sulaiman MKAM et al. Medical and the Architecture of Total Wellness The Potential and Development in Malaysia.World Academy of Science, Engineering and Technology 2010; 53: 1116-1119.

20. Khullar, D. Bad Hospital Design is Making Us Sicker. New York Times. 2017. https://www.nytimes.com/2017/02/22 /well/live/bad-hospital-design-ismaking-us-sicker.html (Assessed 19 August 2018)

21. Haron SN, Alam S. Exploration of Usability Issues in Malaysia Public Hospital Spatial Design: Pilot Study. International Journal of Applied Science and Technology 2011; 1(4): 127-134. 
22. Nawawi NM. In quest for Malaysian healthcare Space Standards: Are We Any Different? Labour Delivery Rooms as Bases for Comparative Study. 2015. https://www.researchgate.net/profile/ Norwina_Mohd_Nawawi/publication/23 6852690_Title_In_quest_for_Malaysian_ healthcare_space_standards_Are_we_a ny_different_-

Labour_Delivery_Rooms_as_bases_for_c omparative_study/links/02e7e5196f911 6797a000000.pdf (Assessed 8 February 2018)

23. Awang Z. SEM Made Simple: A gentle approach to learning structural equation modeling. Selangor, MY: MPWS Rich Publication 2015.

24. Browne MW, Cudeck R. Alternative ways of assessing model fit. Sage focus editions 1993; 154: 136-136.

25. Joreskog K, Sorbom D. Analysis of Linear Structural Relationships by the Method of Maximum Likelihood, User's Guide. Scientific Software: Mooresville, IN 1984.

26. Tanaka JS, Huba GJ. A fit index for covariance structure models under arbitrary GLS estimation. British Journal of Mathematical and Statistical Psychology 1985; 38(2): 197-201.

27. Bentler PM. Comparative fit indexes in structural models. Psychological bulletin 1990; 107(2): 238.

28. Bentler PM, Bonett DG. Significance tests and goodness of fit in the analysis of covariance structures. Psychological bulletin 1980; 88(3): 588.

29. Bollen KA. A new incremental fit index for general structural equation models. Sociological Methods \& Research 1989; 17(3): 303-316.

30. Marsh HW, Hocevar D. Application of confirmatory factor analysis to the study of self-concept: First-and higher order factor models and their invariance across groups. Psychological bulletin 1985; 97(3): 562.

31. Hair JF, Black WC, Babin BJ, et al. SEM: an introduction. Multivariate data analysis: a global perspective. Pearson Education: Upper Saddle River 2010: 629-686.

32. Malhotra NK, Birks DF. Marketing research: An applied approach. Pearson education 2007: 732-733.
33. Sekaran U. (2003) Research methods for business: a skill building approach. Willey, New York. 